\title{
The contribution to tectonic subsidence by groundwater abstraction in the Pingtung area, southwestern Taiwan as determined by GPS measurements
}

\author{
Jyr-Ching $\mathrm{Hu}^{\mathrm{a}, *}$, Hao-Tsu Chu ${ }^{\mathrm{b}}$, Chin-Shyong Hou ${ }^{\mathrm{a}, \mathrm{b}}$, Tzu-Hua Lai ${ }^{\mathrm{b}}$, \\ Rou-Fei Chen ${ }^{\mathrm{c}}$, Pei-Fen Nien ${ }^{\mathrm{a}}$ \\ ${ }^{a}$ Department of Geosciences, National Taiwan University, No. 1, Sec. 4, Roosevelt Road, Taipei 106, Taiwan, ROC \\ ${ }^{\mathrm{b}}$ Central Geological Survey, MOEA, P.O. Box 968, Taipei, Taiwan, ROC \\ 'Observatoire Océanologique de Villefranche-sur-Mer, Université P. \& M. Curie, France
}

Available online 28 October 2005

\begin{abstract}
The three sets of Global Positioning System (GPS) data collected from 1996 to 1999 are used to investigate the contribution to tectonic subsidence by groundwater abstraction in the Pingtung plain, southwestern Taiwan. The horizontal station velocities varied from 32 to $54 \mathrm{~mm} / \mathrm{yr}$ for azimuths ranging from $247.2^{\circ}$ to $272.6^{\circ}$ with respect to the permanent station S01R located in the Penghu islands. In the central and western part of the study area, GPS stations move generally towards the west, whereas in the Kaohsiung-Pingtung coastal area, the displacement vectors demonstrate a clear counter-clockwise deviation towards the SW. The southern part of the offshore coastal area shows remarkable extension rates of $0.6-2.0 \mu$ strain/yr along azimuth $015-020^{\circ}$. The significant southward increase of extensional strain rates is attributed to the lateral extrusion of blocks bounded by major discontinuities in the study area. For the vertical movement, the station velocities are from $\sim 13$ to $-25 \mathrm{~mm} / \mathrm{yr}$. Significant subsidence rates from $\sim 11$ to $\sim 25 \mathrm{~mm} / \mathrm{yr}$ have been observed. These results clearly demonstrate the existence of transtensional deformation and the southward increase of extensional deformation in the along-strike direction throughout the study area. The comparison with the pattern of Holocene subsidence rates and the isopach of fine-grained sediments suggest that about $75 \%$ of this subsidence may result from the decrease in groundwater levels induced by overpumping. These localized anthropogenic activities contributed to the natural risk that results from tectonic subsidence associated with tectonic extrusion and lateral extrusion at the southern tip of the Taiwan collision belt.
\end{abstract}

(C) 2005 Elsevier Ltd and INQUA. All rights reserved.

\section{Introduction}

Land subsidence resulting from groundwater abstraction has been observed in the world (Hix, 1995; Sun et al., 1999). Over-pumping of groundwater is thus a major concern in some coastal regions of Taiwan (Hsu, 1998; Liu et al., 1999; Fan, 2001). Groundwater has been abundantly used as an alternative to surface water, especially in the southwestern coastal region where the efficiency of surface water resource is severe due to aquaculture and industrial utilization since the 1970s (MOEA, 1997). Problems of land subsidence in some coastal areas, with induced frequent flooding and infrastructure failure, have since

\footnotetext{
*Corresponding author. Tel.: + 886223634860 ; fax: + 886223636095 .

E-mail address: jchu@ntu.edu.tw (J.-C. Hu).
}

resulted in serious economic loss. In Taiwan, the total area affected by subsidence because of excessive groundwater abstraction has exceeded $1890 \mathrm{~km}^{2}$. According to a study on land subsidence in the coastal areas of the Pingtung County (MOEA, 1987), using aerial photographs from 1959 to 1985 , the total area affected is about 10,347 ha.

Geodetic levelling is a common technique for monitoring land subsidence on a long-term basis. However, satellite geodesy, especially the Global Positioning System (GPS), has become a powerful method for geodetic monitoring over large areas (Dodson, 1995), with significantly increasing accuracy. Using survey mode GPS, a network of stations take measurements periodically, typically once or twice a year, over long periods. This was done in Taiwan, where accurate relative positioning with GPS allowed for detection of crustal deformation. For instance, to quantify 
the horizontal present-day deformation across the complex convergent plate boundary zone of Taiwan, 141 stations of the "Taiwan GPS Network" were used to achieve four to six surveys between 1990 and 1995 using dual-frequency geodetic receivers ( $\mathrm{Yu}$ et al., 1997). However, analysis of vertical motion in the Pingtung plain, the coverage from these GPS stations was too sparse to allow for good quantification of deformation at the $1-10 \mathrm{~km}$ scale. For this purpose, a dense network has been established in 1996 in the Kaohsiung and Pingtung areas, which allowed determination of crustal deformation of tectonic origin mixed with local subsidence resulting from groundwater with- drawal. In this study, the investigators aim to characterize the deformation patterns and the local subsidence in the Pingtung plain (Fig. 1), based on unpublished data from extensive GPS survey conducted between 1996 and 1999.

\section{Tectonic and geological backgrounds of the Pingtung area}

Southern Taiwan and its offshore areas are currently undergoing incipient collision (Lallemand and Tsien, 1997). It is located in the transition zone between subduction to the south and collision to the north (Fig. 1). It corresponds to the southern part of the

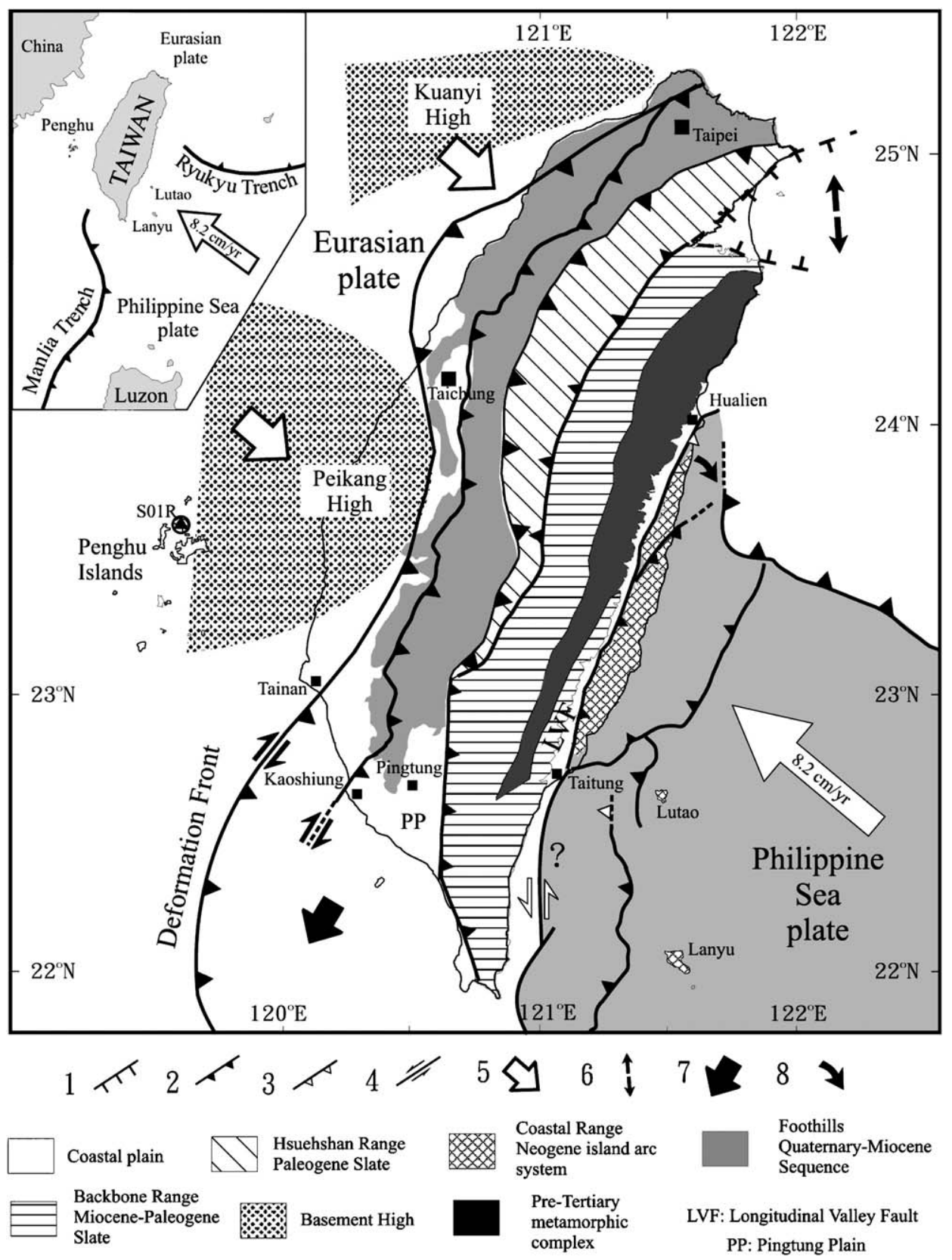

Fig. 1. Tectonic framework and main structural units in Taiwan (after Teng, 1990; Hu et al., 2001; Lacombe et al., 2001; Malavieille et al., 2002). Large open arrow shows the direction and velocity of plate convergence of Philippine Sea plate and Eurasian plate relative to the South China block (Yu et al., 1997, 1999). Major thrust faults with triangles are on the upthrust side. Numbers indicate 1, normal fault; 2, thrust fault (active); 3 , thrust fault (inactive); 4 , strike-slip fault; 5 , indenter of rigid promontory at the front of the active belt; 6 , back-arc opening; 7 , tectonic escape; 8 , migration of the thrust front. 
Plio-Pleistocene foreland basin in response to lithospheric flexure, which primarily results from the tectonic loading of the Central Range (Lin and Watts, 2002). The Pingtung plain covers an area of $1210 \mathrm{~km}^{2}$ and in map view exhibits a rectangular shape. In cross section, it shows the filling of unconsolidated sediments of the late Pleistocene and the Holocene. Most of these sediments consist of coastal to estuarine sand and mud, with abundant shallow marine to lagoonal shells and foraminifers (Shyu, 1999). The Pingtung plain is bounded by low hills of deformed Quaternary sediments to the north and the west. The metamorphosed Tertiary rocks of the lofty Central Mountain Range border to the east. To the south, it opens to the Taiwan Strait. Wu (1993) suggested the Pingtung basin is a piggyback basin because the sediments are derived from the uplifted region of the Taiwan orogene and are confined by the Chaochou and Chishan Faults (Fig. 1). Chiang et al. (2004) suggested the Pingtung basin is located at the wedge-top depozone of the southern Taiwan foreland basin system.

The most significant geomorphologic feature of the Pingtung plain is the straight, N-S trend of the Chaochou Fault escarpment, which separates the alluvium plain and the high mountains. East of the Chaochou Fault, the mountains are mainly composed of EoceneMiocene argillite, slate and meta-sandstone. Based on tectonic analysis of outcrop-scale faults, a predominant transtensional tectonic regime with NNE to NE extension and ESE to SE compression was reconstructed on the eastern side of the Chaochou Fault (Chan et al., 2000). The transition from transpression to recent transtension was also highlighted along the Chaochou Fault, and is probably related to the transition from collision to subduction, which highlights the active extrusion of the study area towards the southeast (Lacombe et al., 1999, 2001).

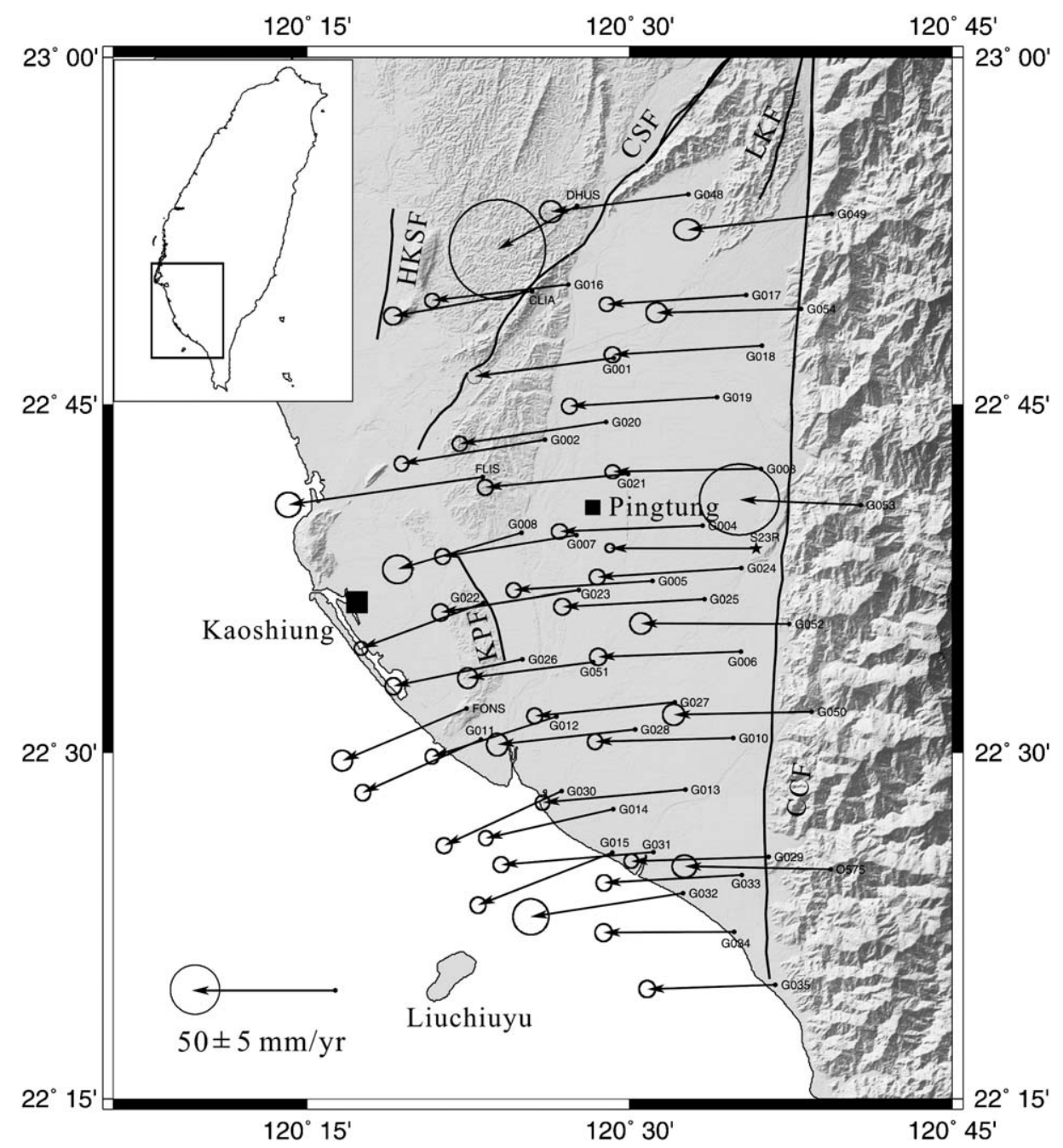

Fig. 2. Horizontal velocity field of GPS stations in Pingtung plain relative to Paisha, Penghu (S01R) from 1996 to 1999. Locality of S01R, see Fig. 1. The $95 \%$ confidence ellipse is shown at the tip of each velocity vector. Solid star indicates permanent GPS station. Solid circles are survey mode stations. Thick lines are active faults. Shaded topography is based on $40 \mathrm{~m} \times 40 \mathrm{~m}$ DEM. CCF: Chaochou Fault; CSF: Chishan Fault; LKF: Liukuei Fault; HKSF: Hsiaohangshan Fault; FSF: Fengshan Fault. 


\section{The Pingtung GPS Network}

In order to analyse the present-day crustal deformation and land subsidence in the Pingtung area, the "Pingtung GPS Network" covering the Pingtung-Kaohsiung area was established in 1995 by the Central Geological Survey, Ministry of Economic Affairs (Fig. 2). It is composed of 48 annually surveyed stations and one permanent, continuously monitoring station (S23R). During the period from August 1995 to August 1999, the mobile stations of the network were surveyed 3-4 times with dual-frequency geodetic GPS receivers. The changes in baseline components derived from these repeated and continuous GPS measurements provided accurate estimates of the relative velocities of GPS stations in the study area. In each survey, four to eight stations were observed simultaneously with dual-frequency geodetic receivers (Trimble 4000 SSE Geodetic Surveyor). A station was usually active during more than two sessions, each session being composed of $6-14 \mathrm{~h}$ of GPS data acquisition from all available satellites rising higher than a $15^{\circ}$ elevation angle. The sampling interval was $15 \mathrm{~s}$. Daily solutions were computed for continuous GPS data. The ionosphere-free linear combination of observations at the L1 and L2 frequencies are employed as the basis for estimating the station coordinates and baseline solutions.

We have processed the observed data with the official final precise ephemerides distributed by the IGS. All available temporary measurements and continuous recordings of GPS data were processed with the Bernese GPS software (v.4.2) developed at the Astronomical Institute of the University of Berne (Hugentobler et al., 2001). The observed data in each epoch survey were processed session by session to obtain the baseline solutions for all combinations of any two stations in the same session. The scatter of GPS measurement series taken over several years can be employed as a relative indicator of precision. This long-term repeatability shows the effects of slowly varying systematic errors resulting from propagation delay, multipath, or fiducial network inconsistencies. To a first

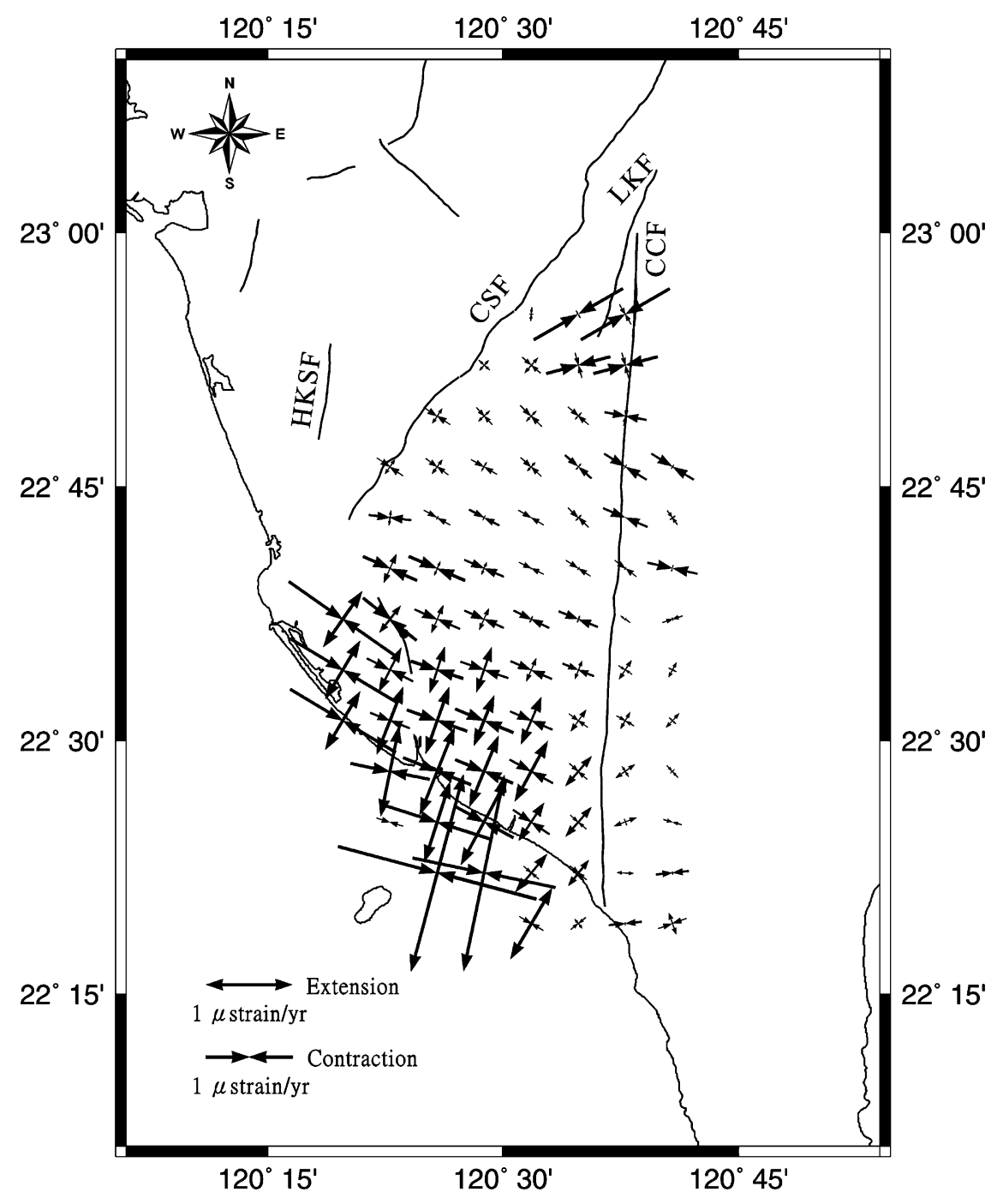

Fig. 3. Principal strain rates in the Pingtung area. Convergent arrows denote contraction, whereas divergent arrows represent extension. Thick grey lines indicate the fault traces based on data of MOEA (Lin et al., 2000). 
approximation, assuming steady motion between stations during the 4-yr period, the scatter of data points was defined relative to a best-fit straight line on the plot of baseline components versus time (Dixon, 1991; Segall and Davis, 1997). The repeatability of baseline component (east, north, and vertical) or baseline length is obtained from the root-mean-square scatter about the linear trend. The baselines range from 3 to $21 \mathrm{~km}$ in length, most of them being shorter than $10 \mathrm{~km}$. The average rates of length change of each baseline between nearby stations, which are usually observed in the same session, are determined from linear regression in time. For baseline lengths in the range of $3-21 \mathrm{~km}$, the standard deviations were $3-6 \mathrm{~mm}$ for the north component, $3-6 \mathrm{~mm}$ for the east component and $10-15 \mathrm{~mm}$ for the vertical component.

\section{Results and discussion}

Our GPS surveys have provided a complete velocity field of SW Taiwan relative to the Paisha station of the Penghu archipelago, which belongs to the stable continental shelf. Horizontal GPS displacement velocities display the trends of variation in the investigated area. The station velocities range between 31 and $56 \mathrm{~mm} / \mathrm{yr}$, with azimuths ranging between $245^{\circ}$ and $273^{\circ}$ with respect to the permanent station S01R. Both horizontal and vertical GPS displacement velocities display the trends of variation in the investigated area (Figs. 2 and 4). For the horizontal velocity field, the station velocities decrease westwards and gradually increase southwards. In terms of velocity vector trends, there is a contrast in kinematics in the study area. In the central and western part of the study area, the GPS stations move mostly towards the west, whereas in the Kaohsiung and Pingtung coastal area the displacement vectors show a clear deviation toward the southwest (Fig. 2). As pointed out by Hu et al. (1997, 2001), this significant counter-clockwise rotation of displacement velocity vectors is related to transtensional deformation, and reflects the along-strike southward increase in extensional deformation in southwest Taiwan, in the transition zone from collision to subduction.

The changes in baseline lengths from the repeated GPS surveys in the Pingtung area are used to assess the spatial variation of the horizontal crustal strain over the region. It

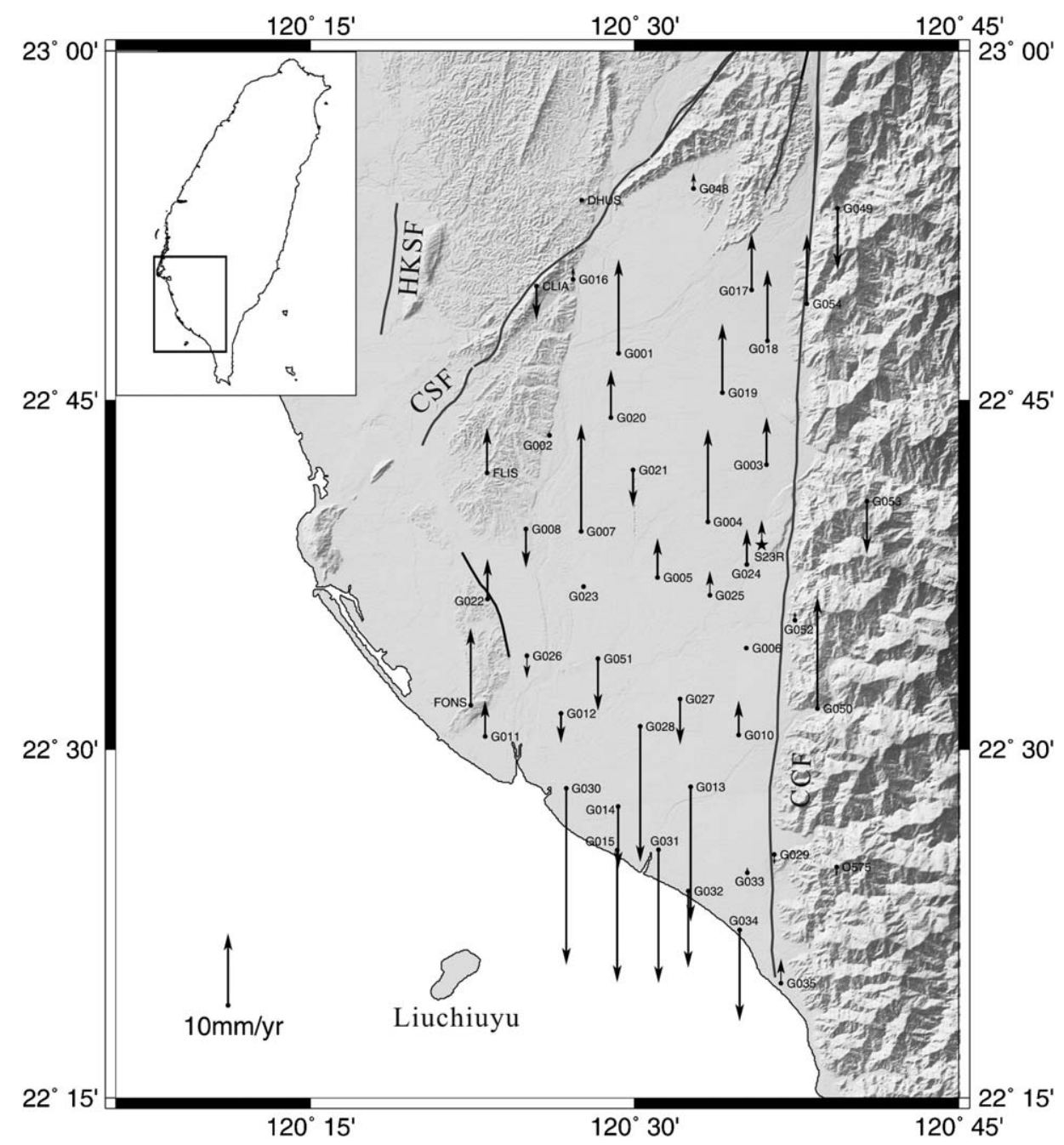

Fig. 4. Vertical velocities of GPS stations in the Pingtung plain relative to Paisha, Penghu (S01R) from 1996 to 1999. Symbols are the same as Fig. 2. 
is assumed that, spatially, the crustal strain accumulates uniformly over each grid, and that the rate of strain accumulation is constant over the time period considered. The most prominent feature of the strain distribution patterns in the study area certainly corresponds to the significant extension in the coastal region of the Pingtung plain. The southern parts of the offshore coastal area show remarkable extension rates of $0.6-2.0 \mu$ strain/yr in an azimuth $015-020^{\circ}$ (Fig. 3). By contrast, in the north and central part of the Pingtung plain, the small contractions mostly trend WNW-ESE directions. This significant southward increase of the extensional strain rates is attributed to the lateral extrusion of blocks bounded by major discontinuities in the study area (Fig. 1). These results are in general agreement with the previous models of lateral extrusion due to the low lateral confining conditions related to the Manila subduction zone as a free boundary or/and the presence of prominent Peikang High as a rigid indenter ( $\mathrm{Lu}$ and Malavieille, 1994; $\mathrm{Hu}$ et al., 1997, 2001; Lu et al., 1998; Lacombe et al., 1999, 2001; Bos et al., 2003). Based on the rigid blocks models (Angelier et al., 1999; Lacombe et al., 2001), the escaping area comprises four rigid blocks moving towards the SW along major discontinuities with both lateral and reverse shears. These discontinuities comprise the right-lateral reverse motion of the Deformation Front, right-lateral reverse motion of the Chishan fault, left-lateral reverse motion of the Kaoping Fault and left-lateral reverse motion of the Chaochou Fault (Fig. 1). Based on the inversion of fault slip and continuous deformation deduced from GPS data in Taiwan (Yu et al., 1997), Bos et al. (2003) also presented a surface deformation model for southern Taiwan. This model exhibited a strain pattern with $\mathrm{E}-\mathrm{W}$ contraction accompanied by a southward increase of predominantly $\mathrm{N}-\mathrm{S}$ oriented extension.

The vertical deformation revealed by our GPS measurements is distributed in two distinct regions, north and south, with dominant uplift and subsidence respectively (Figs. 4 and 5). Chen (1984) pointed out that tectonically the area north of Pingtung area is characterized by uplift whereas the coastal area of Pingtung plain is dominated by subsidence. On the basis of GPS measurements, a

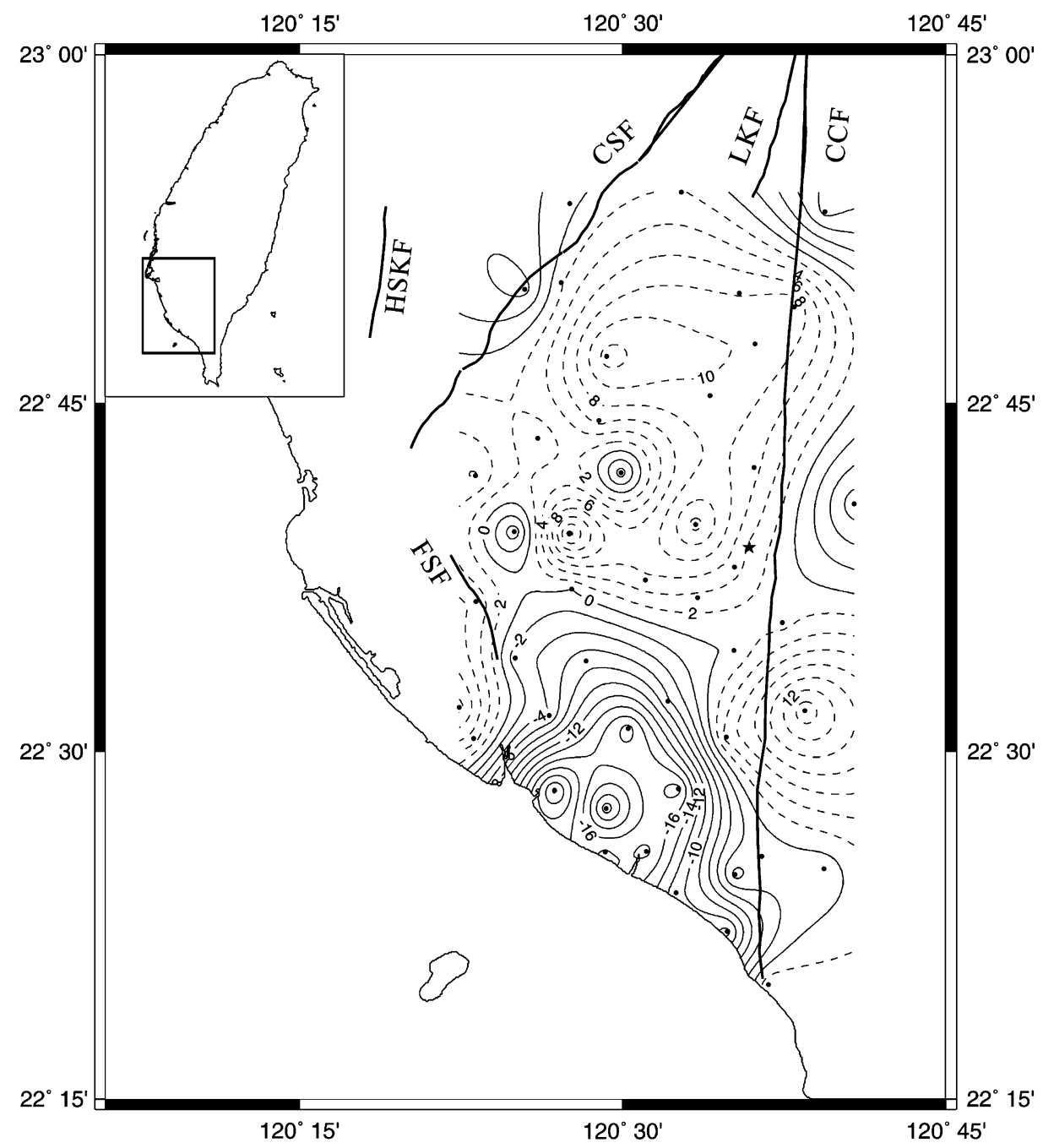

Fig. 5. Contours of vertical velocities of GPS stations in the Pingtung plain relative to Paisha, Penghu (S01R) from 1996 to 1999. Contour interval is $2 \mathrm{~mm} / \mathrm{yr}$. Dotted contours indicate uplift and solid contours are subsidence. Symbols are the same as Fig. 2. 


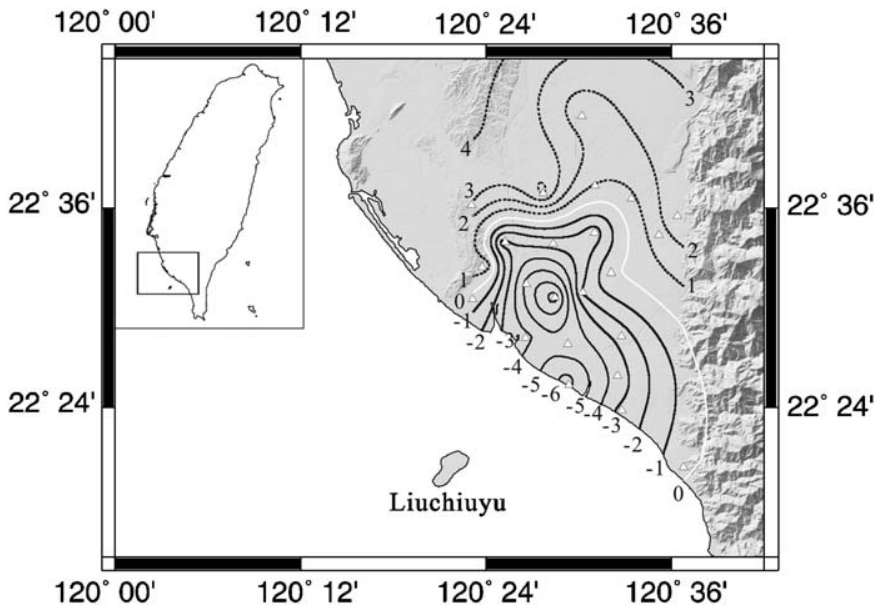

Fig. 6. Contours of vertical uplift and subsidence rates $(\mathrm{mm} / \mathrm{yr})$ of Holocene based on radiocarbon dating and drill cores (Modified after Lai et al., 2002; Lai and Hsieh, 2003). White line denotes the boundary of uplift and subsidence region. Solid lines indicate subsidence whereas dotted lines represent uplift. Solid triangles indicate the localities of well sites.

significant subsidence rate from $\sim 11$ to $\sim 25 \mathrm{~mm} / \mathrm{yr}$ is observed in the southern Pingtung plain. The maximum subsidence rate is compatible with the value of $25 \mathrm{~mm} / \mathrm{yr}$ previously calculated based on conventional geodesy from 1914 to 1979 (Chen, 1984). This significant subsidence partly results from the large groundwater pumping for aquacultural purposes. Taking into account a recent study of groundwater table evolution (Kuo et al., 2001), the total subsidence of the southern Pingtung plain should be attributed to the mixed effects of regional tectonic tilting towards the southwest and local over-abstraction of groundwater. On a longer time scale, Lai et al. (2002) quantified Holocene subsidence rates in the southern Pingtung plain, based on radiocarbon dating and drill cores (Fig. 6). Furthermore, the Holocene subsidence pattern is consistent with the isopach of fine-grained sediments in the study area (Fig. 7). Based on their study, the average subsidence rate is about $4 \mathrm{~mm} / \mathrm{yr}$ with a subsidence pattern similar to that of Fig. 5. This long-term average subsidence rate for the Holocene in southern Pingtung is about $2-6$ times smaller than the observations derived from GPS measurements from 1996 to 1999 . We infer that this regional subsidence is due to both the prominent groundwater level decrease which causes rapid subsidence of the coastal zone of the Pingtung plain, as well as the transtensional deformation associated with the tectonic extrusion.

\section{Conclusion}

Four years of GPS measurements with three campaigns have shown that subsidence in the Pingtung-Kaohsiung area is dominated by transtensional crustal deformation due to tectonic extrusion. The horizontal station velocities varied from 32 to $54 \mathrm{~mm} / \mathrm{yr}$ in azimuths ranging from $247^{\circ}$

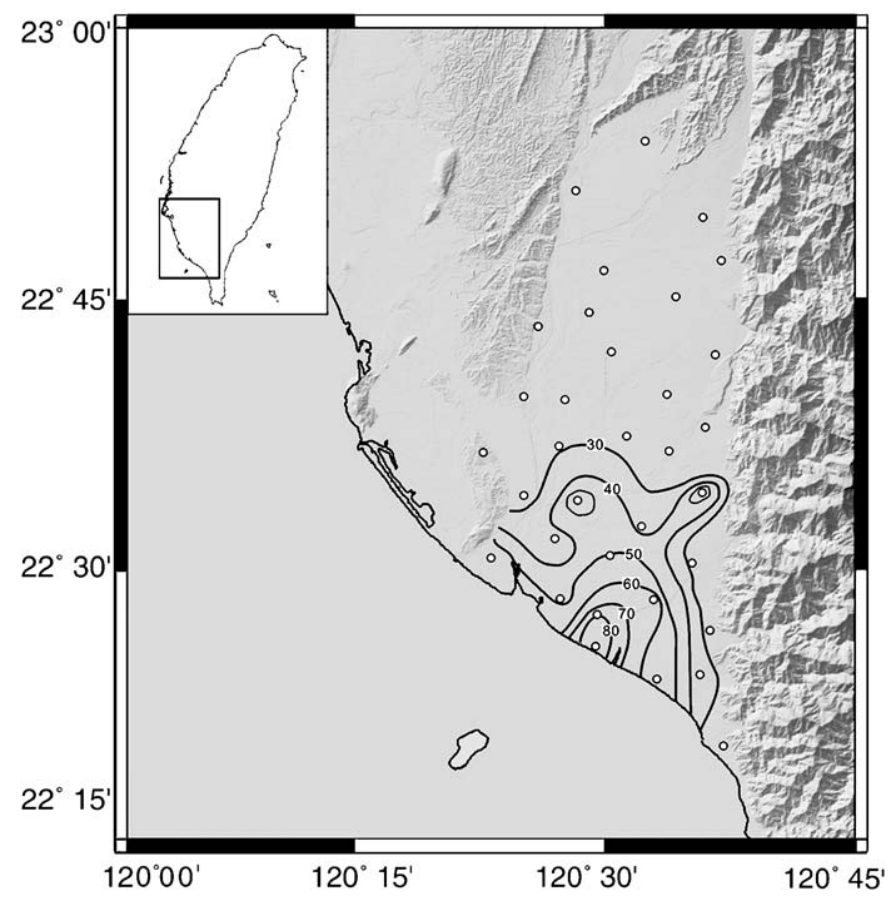

Fig. 7. Contours of percentage for depositional isopach of fine-grained sediments in subsidence area (Modified after Huang et al., 1998). Open circles indicate the localities of well sites.

to $273^{\circ}$ with respect to the permanent station (S01R) located on the stable continental shelf. The southern parts of offshore coastal area show remarkable extension rates of $0.6-2.0 \mu \mathrm{strain} / \mathrm{yr}$ in an azimuth $015-020^{\circ}$. This significant southward increase of extensional strain rates is attributed to the lateral extrusion of blocks bounded by major discontinuities in the study area. For the vertical movement, the station velocities range from 13 to $-25 \mathrm{~mm} / \mathrm{yr}$. There are 20 stations with recorded velocities showing subsidence in the southern part of the Pingtung plain. Significant subsidence rates from $\sim 11$ to $\sim 25 \mathrm{~mm} / \mathrm{yr}$ have been observed. These results clearly demonstrate the existence of transtensional deformation and the southward increase of extensional deformation in the along-strike direction of the whole study area. The comparison with the pattern of Holocene subsidence rates (about $-4 \mathrm{~mm} / \mathrm{yr}$ in the same area) and isopach of fine-grained sediments suggests that about $75 \%$ of this subsidence may result from the decrease in groundwater levels induced by overpumping. These localized anthropogenic activities contributed to the natural risk that results from tectonic subsidence associated with tectonic extrusion and lateral extrusion at the southern tip of the Taiwan collision belt.

\section{Acknowledgements}

We are grateful to Margot Böse, Alexander Koh and Serge Shaprio for constructive comments that led us to improve the manuscript. The authors would like to thank Chia-Yu Lu, Yu-Chang Chan, Meng-Long Hsieh, Shui-Bei 
$\mathrm{Yu}$, Ching-Huei Kuo and Benoit Deffontaines for the suggestions and discussions. This research was supported by grants from the National Science Council of Taiwan (NSC 91-2119-M-002-020) and the Central Geological Survey of the MOEA. Some figures were produced using the Generic Mapping Tools written by Paul Wessel and Walter H.F. Smith (Wessel and Smith, 1998).

\section{References}

Angelier, J., Chu, H.T., Lee, J.C., Hu, J.C., 1999. Active faulting and earthquake risk: the Chihshang Fault case, Taiwan. Journal of Geodynamics 29, 151-185.

Bos, A.G., Spakman, W., Nyst, M.C.J., 2003. Surface deformation and tectonic setting of Taiwan inferred from a GPS velocity field. Journal of Geophysical Research 108 (B10), 2458.

Chan, Y.-C., Lu, C.-Y., Lee, J.-C., 2000. Orogen-parallel shearing in ongoing mountain building: a case study from the southeastern Central Range of Taiwan. Eos. Transactions of AGU, Fall Meeting Supplement Abstract, 81.

Chen, H.-F., 1984. Crustal uplift and subsidence in Taiwan: an account based upon retriangulation results. Special Publication of the Central Geological Survey 3, pp. 127-140.

Chiang, C.-S., Yu, H.-S., Chou, Y.-W., 2004. Characteristics of the wedgetop depozone of the southern Taiwan foreland basin system. Basin Research 16, 65-78.

Dixon, T.H., 1991. An introduction to the Global Positioning System and some geological applications. Review of Geophysics 29, 249-276.

Dodson, A.H., 1995. GPS for height determination. Survey Reviews 33, 66-76.

Fan, K.-L., 2001. Some coastal environmental problems in Taiwan. Acta Oceanographica Taiwanica 39, 1-10.

Hix, G.L., 1995. Land subsidence and ground water withdrawal. Water Well Journal 49, 37-39.

Hsu, S.-K., 1998. Plan for a groundwater monitoring network in Taiwan. Hydrogeological Journal 6, 406-415.

Hu, J.-C., Angelier, J., Yu, S.-B., 1997. An interpretation of the active deformation of southern Taiwan based on numerical simulation and GPS studies. Tectonophysics 274, 145-169.

Hu, J.-C., Yu, S.-B., Angelier, J., Chu, H.-T., 2001. Active deformation of Taiwan from GPS measurements and numerical simulations. Journal of Geophysical Research 106, 2265-2280.

Huang, C.-C., Chiang, C.-J., Lai, Y.-H., 1998. The hydrogeological framework and groundwater system model of Pingtung Plain. In: Proceedings of the Symposium on Groundwater and Hydrogeology of the Pingtung Plain, Taipei, pp. 139-152.

Hugentobler, U., Schaer, S., Fridez, P., 2001. Bernese GPS Software, Version 4.2. Astronomical Institute, University of Berne, 515pp.

Kuo, C.-H., Chan, Y.-C., Wang, C.-H., 2001. Subsidence: over withdrawal groundwater, tectonic or both? Eos. Transactions of AGU, Fall Meeting Supplement Abstract, 82, F479.

Lacombe, O., Mouthereau, F., Deffontaines, B., Angelier, J., Chu, H.-T., Lee, C.-T., 1999. Geometry and Quaternary kinematics of fold-andthrust units of southwestern Taiwan. Tectonics 18, 1198-1223.

Lacombe, O., Mouthereau, F., Angelier, J., Deffontaines, B., 2001. Structural, geodetic and seismological evidence for tectonic escape in SW Taiwan. Tectonophysics 333, 323-345.
Lai, T.-H., Hsieh, M.-L., 2003. Late-Quaternary Vertical Rock-movement Rates of the Coastal Plains of Taiwan. 2003 Annual Meeting Geological Society, Taipei, p. 119.

Lai, T.-H., Hsieh, M.-L., Liew, P.-M., Chen, Y.-G., 2002. Holocene rock uplift and subsidence in the coastal area of Taiwan. Eos, Transactions of AGU, Fall Meeting Supplement Abstract, 83, F1280.

Lallemand, S.E., Tsien, H.-H., 1997. An introduction to active collision in Taiwan. Tectonophysics 274, 1-4.

Lin, A.T., Watts, A.B., 2002. Origin of the west Taiwan basin by orogenic loading and flexure of a rifted continental margin. Journal of Geophysical Research 107 (B9), 2185-2203.

Liu, C.-W., Lin, W.-S., Shang, C., Liu, S.-H., 1999. The effect of clay dehydration on land subsidence in the Yun-Lin coastal area, Taiwan. Environmental Geology 40, 290-296.

Lin, C.-W., Chang, H.-C., Lu, S.-T., Shih, T.-S., Huang, W.-J., 2000. An introduction of the active faults of Taiwan. Central Geological Survey Special Publication 13 122pp.

Lu, C.-Y., Malavieille, J., 1994. Oblique convergence, indentation and rotation tectonics in the Taiwan Mountain Belt: insights from experimental modeling. Earth and Planetary Science Letters 121, $477-494$

Lu, C.-Y., Jeng, F.-S., Chang, K.-J., Jian, W.-T., 1998. Impact of basement high on the structure and kinematics of western Taiwan thrust wedge: insights from sandbox models. Terrestrial, Atmosphere and Oceanic Sciences 9 (3), 533-550.

Malavieille, J., Lallemand, S.E., Dominquez, S., Deschamps, A., Lu, C.Y., Liu, C.-S., Schnürle, P., 2002. Arc-continent collision in Taiwan: new marine observations and tectonic evolution. In: Byrne, T.B., Liu, C.-S. (Eds.), Geology and Geophysics of an Arc-Continent Collision, Taiwan, Boulder, CO. The Geological Society of America Special Paper 358, pp. 187-211.

MOEA (Ministry of Economic Affairs), 1987. Study on the Subsidence of Land in Coastal Areas in Pingtung County, 77pp.

MOEA (Ministry of Economic Affairs), 1997. The Execution of Land Subsidence Prevention and Reclamation Plan in 1997 (in Chinese). MOEA, Taipei, Taiwan.

Segall, P., Davis, J.L., 1997. GPS applications for geodynamics and earthquake studies. Annual Review of Earth Planetary Science 25, 301-336.

Shyu, B.H., 1999. The sedimentary environment of southern Pingdong plain since the last glacial. Master Thesis, National Taiwan University, Taipei, 212pp.

Sun, H., Grandstaff, D., Shagam, R., 1999. Land subsidence due to groundwater withdrawal: potential damage of subsidence and sea level rise in southern New Jersey, USA. Environmental Geology 34, 290-296.

Teng, L.S., 1990. Geotectonic evolution of late Cenozoic arc-continent collision in Taiwan. Tectonophysics 183, 57-76.

Wessel, P., Smith, W.H.F., 1998. New, improved version of the Generic Mapping Tools Released. EOS Transactions of AGU 79, 579.

Wu, L.-C., 1993. Sedimentary basin succession of the upper Neogene and Quaternary Series in the Chishan area, southern Taiwan and its tectonic evolution. Ph.D. Thesis, National Taiwan University, 212pp.

Yu, S.-B., Chen, H.-Y., Kuo, L.-C., 1997. Velocity field of GPS Stations in the Taiwan area. Tectonophysics 274, 41-59.

Yu, S.-B., Kuo, L.-C., Punongbayan, R.S., Ramos, E.G., 1999. GPS observation of crustal deformation in the Taiwan-Luzon region. Geophysical Research Letters 26, 923-926. 